\title{
Right Posterior Apical Transition Zone of Prostate
}

National Cancer Institute

\section{Source}

National Cancer Institute. Right Posterior Apical Transition Zone of Prostate. NCI

Thesaurus. Code C128585.

The region of the prostate that is located on the anatomical right side of the posterior portion of the apical division of the transition zone. 